\title{
Who is on our side? Complexities of national identification among native and immigrant youth in Catalonia
}

\author{
Ann E. Wilson-Daily a \\ Markus Kemmelmeier b \\ ${ }^{\text {a }}$ Faculty of Education, Universitat de Barcelona, Barcelona, Spain \\ b Interdisciplinary Social Psychology Ph.D. Program, University of Nevada, Reno, United \\ States
}

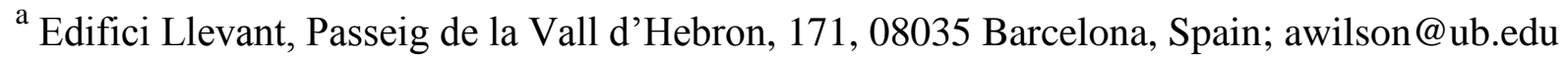
(corresponding author)

b Mail Stop 1300, Reno, NV 89557, United States; markusk@unr.edu

\section{Citing this paper}

Please note that this is a Post-Print version that may differ from the final published version. If citing, it is advised that you check and use the publisher's definitive version for pagination purposes and editor corrections.

Citation for "online first" version (APA)

Wilson-Daily, A. E., \& Kemmelmeier, M. (2020). Who is on our side? complexities of national identification among native and immigrant youth in Catalonia. Journal of Youth Studies. Advance online publication. https://doi.org/10.1080/13676261.2020.1784856

Ann E. Wilson-Daily, ORCiD: 0000-0001-5994-6210

Markus Kemmelmeier, ORCiD: 0000-0002-1612-5903

This work was supported by the RecerCaixa program, under Grant number 2012-ACUP-00185; and the Spanish Ministry of Economy and Competitiveness, under Grant number EDU2015-65621-C3-3R. The authors would like to thank the DHIGECS research group members for their role in data collection. The would also like to thank the anonymous reviewers for their helpful suggestions, and attendees at the EASP-SPSSI Joint Meeting: "To be both (and more)": Immigration and identity multiplicity in Utrecht, the Netherlands for their comments, especially Anca Minescu. 


\section{Who is on our side? Complexities of national identification among native and immigrant youth during the struggle over Catalan independence}

Youth in Catalonia are caught in the middle of a hotly contested political conflict over the region's possible independence from Spain. Focusing on a large sample of secondary school students ( $n=1550 ; 24.6 \%$ immigrants) from 30 schools, we use multilevel modelling to investigate identification with competing national identities and their implications for xenophobia. The larger social context is reflected in native students viewing Catalan and Spanish identifications as incompatible with one another, whereas this is not the case for immigrant students, who are much more likely to identify as both Catalan and Spanish, albeit at a lower level. Investigating the perceived basis of what makes someone Catalan, native students viewed their national identity to be a matter of both ascription (e.g., birth, legal status) and practice (e.g., embracing traditions, personal feelings), whereas the identifications of both Muslim and non-Muslim immigrants were exclusively based on viewing Catalan identity as a matter of practice. Conceiving of Catalan identity as a matter of practice was also linked to lower levels of xenophobia. Our findings are consistent with the conception of Catalan national identity as cosmopolitan and welcoming to immigrants, in line with outreach of the Catalan independence movement seeking to attract support.

Keywords: national identity; students; immigration; adolescence; Catalonia 


\section{Introduction}

Periods of political turmoil often reinforce pre-existing national attachments (Gibler, Hutchison, \& Miller, 2012; Klandermans, 2014), especially when this turmoil occurs during adolescence (Hayes \& McAllister, 2009; Wainryb \& Recchia, 2015; also Schwartz et al., 2005). Catalonia, an autonomous region of Spain, has recently been the setting of an often tumultuous struggle toward independence. Following ultimately thwarted efforts to expand Catalan's political autonomy during the first decade of the $21^{\text {st }}$ century (Guibernau, 2013), Catalan residents often feel social pressure to position themselves, in personal conversations or by vote, whether to identify with either Spain or Catalonia (Fernández-i-Marín et al., 2013). Coinciding with an upsurge in popular support for political independence (Tormos, Muñoz, \& Hierro, 2015; Woolard, 2016), Catalans have increasingly identified as “only Catalan.” And even though Catalans are, at least currently, citizens of Spain, there has been a recent large decline in Spanish identification (García, 2013; Tormos et al., 2015), though this decline may have preceded the increase in Catalan identification (Martínez-Herrera, 2002, Serrano, 2013). The result is a process of identity polarization observed elsewhere (Klandermans, 2014).

National identification within Catalonia has been studied extensively in adult populations (e.g., Centre d'Estudis d'Opinió [CEO], 2019¹ ; Hierro \& Gallego, 2018; Tormos et al., 2015), but these studies have largely neglected adolescent viewpoints, which, perhaps counterintuitively, remain relatively stable over time and are therefore worthy of study (e.g., Hooghe \& Wilkenfeld, 2008; Houston et al., 1990). Furthermore, previous work has mostly ignored the viewpoints of the growing, diverse, and relatively young immigration population (IDESCAT, 2014a; 2014b).

In this article, we examine how both native and immigrant youth position themselves regarding national identification during Catalonia's recent nonviolent political conflict within 
its diverse secondary school settings. We are interested to what extent the previously observed identity polarization among adults exists during adolescence, the transitional period from childhood to adulthood, specifically mid-adolescence (i.e., 15-16 year olds). Furthermore, we investigate the implications of different identifications for xenophobia in a region that prides itself as open to diversity and immigration (e.g., Erickson, 2011; Woolard, 2016).

\section{Catalonia and 'rival' national identifications}

Catalonia, with its capital Barcelona, is a region of contemporary Spain with a long history of its own language and political structures. After decades of linguistic and other cultural and political oppression during the Franco dictatorship and previous regimes, the region has gradually gained more autonomy; however, repeated demands for greater autonomy for Catalonia have been impeded throughout the past two decades (Guibernau, 2013). Since the transition to democracy in the late 1970s Catalan is an official language, and the principle language of instruction in schools, which has greatly expanded its use and fluency, especially among youth. For a little over a decade there has been a growing independence movement, including grassroots municipal referenda (starting in 2009), as well as Catalan elections of 2012 and regional elections of 2015, which were touted as quasi-referenda on independence (Martí \& Cetrà, 2016; Orriols \& Rodon, 2016). A controversial 2017 referendum held by the Catalan government was declared illegal by Spain and resulted in the long-term imprisonment of Catalan leaders (Barceló, 2018; "Violent clashes," 2019) and the Spanish government has also imposed direct rule on Catalonia, drastically reducing its autonomy (Garrido-Muñoz, 2018). As one of Spain's more economically vibrant regions, Catalonia has recently experienced a tremendous influx of immigrants mainly from northern Africa, South America, Asia, and Eastern Europe (IDESCAT, 2014b). Between 2000 and 2014 (the latter being the year in which we conducted our research) the immigrant population increased six-fold, representing around $14 \%$ of the Catalan population (IDESCAT, 2014a). This has visibly 
augmented Catalonia's socioeconomic, linguistic, and religious diversity.

Due to Catalonia's status as an autonomous unit within the larger edifice of Spain, concepts of majority and minority groups are blurred. Aside from recent international immigration and those with multi-generation roots in the region, Catalan residents include offspring of Spanish migrants enticed by Catalonia's relative economic vitality. Surges of this regional migration within Spain occurred in the 1960s and 70s (Woolard, 2016). Individuals who either immigrated to Catalonia from other regions of Spain were habitually referred to as "immigrants" themselves. Members of this group may be perceived as a majority or a minority; often depending on the geographic location within Catalonia or the institution in question, as group status varies spatially in terms of power and size (Astor, 2016; Woolard, 2016).

Because of intersecting memberships to Catalonia and Spain, and acute political tensions between the Spanish and Catalan governments, of late many residents of Catalonia feel a need to position themselves as belonging to either one or the other (e.g., Fernández-iMarín et al., 2013). The consequence is identification polarization, as identifying as Catalan is increasingly considered incompatible with identifying as Spanish (e.g., Tormos et al., 2015). As numbers of "Catalan only" identifiers have been increasing (from 17\% in 2005 to $32 \%$ in 2013), the largest group among Catalan residents still identifies to a similar degree as both Catalan and Spanish (35\% in 2015; Hierro \& Gallego, 2018). Newly, these dual identifiers tend to retreat from nonviolent political confrontation in the wake of such conflict (Hierro \& Gallego, 2018). Yet, political support for an independent Catalan nation does not exclusively coincide with "Catalan-only" identification, as many independence supporters identify as both Catalan and Spanish; some even identifying exclusively as Spanish (Serrano, 2013).

\section{Immigrants to Catalonia and negotiating national identifications}

Immigration to Europe and other Western societies presents a number of new challenges both for hosts and newcomers. For immigrants, the relationship between ethnic and national iden- 
tity is in continuous evolution as they interact with host society members and each other, negotiating obstacles, opportunities, and social pressures (Wainryb \& Recchia, 2015). As Tsang et al. (2003, p. 364) write, "How one defines oneself within a context of multiple processes of identification becomes a central task in the immigrant's settlement and integration into the host country".

In the context of an ongoing struggle of national identity and social relations, understandably, immigrants encounter complexities (Repke \& Benet-Martínez, 2018). Whereas in many other countries, immigrants negotiate their relationship with a single host nationality, in Catalonia, national identification might alternately, or conjointly, refer to Spain or Catalonia. If they wish to integrate, immigrants have to negotiate relationships between the two. They might choose to affiliate more closely with one national group or the other, thus positioning themselves in the ongoing identity conflict similarly to native residents. Alternatively, immigrants might identify with different national groups in ways that bypass the existing identity polarization, thus not embracing the aforementioned antagonism between Catalonian and Spanish identities. Instead, their identification may be driven by other forces, such as negative and/or positive personal experiences with different nationally-identifying individuals in Catalonia, a general desire to fit in, or even a lack of awareness that many natives view Catalan and Spanish identification as incompatible. Lastly, traditional cultural attachments to Spain or former Spanish colonies may also facilitate identification with Spain (Petreñas et al., 2019). Importantly, over $23 \%$ of immigrants to Catalonia hailed from Spanish-speaking countries at the time of data collection (IDESCAT, 2014b).

\section{Nature and content of national identities}

Not all national identities are created equal. Whereas high levels of national identification have been tied to negative attitudes toward immigrants, there is no necessary link between national attachment and prejudice (e.g., Adams, 2007; Blad \& Couton, 2009). Kohn's (1944) 
distinction between an ethnic and a civic basis of national identity has long informed the literature. Ethnic identity typically refers to a membership in a cultural group, which is the result of heritage or upbringing, akin to tribal membership. Ethnic identity often means that ethnic 'others' are excluded from the concept of the nation (Billig, 1995; Gilroy, 2002). Identification with ethnically-based versions of national identity is generally linked to negative predictions of immigrants (Kunovich, 2009). Civic notions of national identity refer to a membership based on involvement through acts of citizenship, including contributions to political and community life. These do not invoke ideas of heritage but presume that national identity is permeable and acquirable. Civic identity is often considered to include aspects that are under an individual's control like "feeling" that one is from a nation or speaking the language (see Larsen, 2017; Janmaat, 2006; Jones \& Smith, 2001a, 2001b).

With ongoing efforts toward Catalan autonomy and independence, our interest centres on the nature of Catalan identity and identification. Recent studies have argued that sub-state nations generally tend to be open to immigrants and to their adoption of host national identities with the aim of cultural or political perpetuation (e.g., Blad \& Couton, 2009; Conversi \& Jeram, 2017; Jeram, 2013). Catalonia seems to be no exception in this regard (e.g., Carlà, 2018; Conversi, 1990; Erickson, 2011). Whereas Catalan identity may certainly be based on ancestry and heritage, one would expect Catalan identity to be highly influential as a civic identity as well. Consistent with this idea, Catalan independence supporters have specifically reached out and argued for the inclusion of immigrants (see Carlà, 2018; Franco-Guillén, 2015). The idea of being Catalan reflecting a civic identity has long played a role in Catalan integrationist discourse through the concept of convivència. Erickson (2011) argues that convivència itself is a "vernacular interculturalist project in [Catalonia]... an alternative to both xenophobic and liberal multiculturalist discourses circulating in Europe" (p. 114) where, he argues, both sides work to meet on a sort of middle ground. 
Still, the civic-ethnic conceptualization has received much criticism as an oversimplification. Theorists have argued that most identities pertaining to nations frequently include elements that are both civic and ethnic (e.g., Kymlicka, 2001; Shulman, 2002). Furthermore, the popularity of civic-ethnic framework has enabled, if not encouraged, a mislabelling of stateless nations like Catalonia, Quebec, and Scotland as "ethnic" nationalist projects (Blad \& Couton, 2009; Kymlicka, 2001). Conversi (1990) argued that, compared to the nearby Basque Country, Catalan identity is not based on race or ethnicity, but rather to language use and competence. Because language proficiency can be acquired by new arrivals, a non-ethnic identity is more open and welcoming to immigrants than one based on ethnicity. Erickson (2011) expands: "Catalan identity is rarely considered to reside in genetic or racial origin but in residence, voluntary self-identification, political commitment to regional autonomy, and the use of the Catalan language" (p. 116).

Yet, an open question remains as to if and how immigrants absorb, and even believe, these messages based on their personal experiences at school and elsewhere. Deusdad Ayala (2009) documented rampant teacher-held xenophobic views within Catalan secondary schools (see also Petreñas et al., 2019). Likewise, Gibson et al. (2013) observed:

As in other high schools with a predominantly native Catalan staff and student body, a particular nationalist discourse emerged that prided itself in the lack of racism and discrimination, as these were seen to be un-Catalan. Yet this discourse contradicted the everyday lived experiences of isolation and racialized discrimination among the newcomer students from non-EU countries (p. 102).

Further confusing the situation, Muslims, especially when they are recent immigrants from north African countries or the Middle East, often face rejection and hostility from Spanish identifiers within Catalonia (Astor, 2016; Deusdad Ayala, 2009). Astor (2016) argues that anti-Mosque protests have been held primarily in the peripheral districts of Barcelona in areas with large concentrations of Spanish-identifiers. It is well documented that lower-skilled and 
less-educated natives are especially likely to view immigrants as a threat to their economic well-being (e.g., Hjerm, 2001; Scheve \& Slaughter, 2001). Spanish identifiers, given their recent migrant status and taken as a group overall, are economically disadvantaged compared to Catalan natives (Miley, 2006); and may be more likely to view immigrant groups, as economic competition (see Astor, 2016). This may be especially for Muslim immigrants, who have been arriving in Catalonia over a relatively short span of time and settled primarily in working-class areas with higher concentrations of Spanish-identifying migrants and their descendants.

Although some Catalan nationalists may seek to "recruit" immigrants to share in their national agenda, immigrants are differentially responsive to the invitation. However, little is known about how immigrant adolescents position themselves within Catalonia's complicated identity constellation.

\section{Study overview}

Our research investigates questions of national identification in a large sample of adolescents in Catalonia - the first to focus on this population. Specifically, we examine how the understudied native and immigrant adolescent populations negotiate their attachment to Spain and to Catalonia. These two different dimensions of national identification are likely shaped by a variety of factors discussed in the literature, including social environments, socioeconomic background, as well as understanding of what it means to be Spanish or Catalan.

As a general approach, we rely on multilevel regression; we attempt to study national identification not only as a function of the characteristics of individuals, but also of the social context. Classrooms and schools represent a critical life context for adolescents, which help shape students' relationship to larger society (e.g., Meece \& Eccles, 2010). This is especially true in Catalan high schools, where classes of students are comparably stable across multiple years (see Wilson-Daily et al., 2018). Hence, we consider multilevel regression imperative, if 
only to correctly assess predictors of national identification at individual, classroom and school levels.

A novel contribution of this study is our measure of dual identity, for which we adapt a method originally used in attitude research, specifically, attitudinal ambivalence. We capitalize on the fact that measures of attitudinal ambivalence reflect the simultaneous endorsement of ideas or feelings that many view as incompatible with each other (Thompson \& Zanna, 1995; Priester \& Petty, 1996). Ambivalence is low when participants provide high ratings on one dimension and low on the other, or when a person expresses low ratings on both. However, ambivalence is high when participants provide high ratings on both positive and negative dimensions. Because many people in Catalonia increasingly view identifying as Catalan and as Spanish as incompatible, we repurpose the same method in order to study dual identification, i.e., the extent to which someone might highly identify as both Catalan and as Spanish. Our measure yields high values when a person highly identifies with both the Catalan and Spanish identities simultaneously. It yields low values when the person identifies with only one identity, Catalan or Spanish, but it also yields low values if the person identifies with neither Catalonia nor Spain² (see "Measures" section).

Critically, we also examine the implications of Catalan, Spanish, and dual identification for xenophobia. Because our research addresses how youth absorb messages about Catalan identity, we considered it important to test if viewing being Catalan as a more civic, permeable national identity would promote higher levels of tolerance toward non-natives. This was important as other work has claimed that high levels of identification with civic-type identities can also predict prejudice and exclusion (e.g., Kunovich, 2009). But given that the political discourse in Catalonia focuses on openness toward immigrants, with Catalan identity touted as inclusive and accepting, we hypothesized this would not be the case with Catalan identity. 
With the larger political conflict centred on the status of Catalonia, and with Catalan national identity being a topic of controversy, we assess two different conceptions of Catalan identity, inspired by the ethnic vs. civic distinction, but adapted with subnation distinctiveness in mind (e.g., Blad \& Couton, 2009). Specifically, we assess whether students considered being Catalan a matter of practice or a matter of ascription, based on legal status implied by birth. Perceived group permeability (see Ellemers, 1993; Verkuyten \& Reijerse, 2008) is central to the concept of an "in-practice" Catalan identity, and reflects a non-exclusive idea of nationality as touted by the Catalan independence movement. However, conceptions of nationality resulting from clear criteria which either ascribe Catalan identity to a person or not, are likely more exclusionary.

As mentioned above, our interest lies in whether immigrants identify with Catalonia or Spain, and whether they adopt a similar stance as natives toward the two national identities, especially as far as perceived identity (in)compatibility is concerned. We also anticipate that immigrants' backgrounds matter, with immigrants from traditionally Spanish-speaking countries (e.g., Latin America) presumably less likely to identify as Catalan (Huguet \& Janés, 2008; Petreñas et al., 2019). Similarly, we also compare Muslim and non-Muslim immigrants, who, in our sample mostly hail from Morocco, and to a lesser extent Pakistan, as Muslim immigrants in Europe often face higher levels of prejudice and acrimony than those with other religious backgrounds (e.g., Astor, 2016; Deusdad Ayala, 2009; Reitz et al., 2017).

All of our models include four individual-level demographic predictors: gender, socioeconomic status (SES), immigration status, and the age of arrival in Catalonia when pertinent. Females are often expected to identify less with larger groups such as nations, and be lower in xenophobia (e.g., Verkuyten \& Masson, 1996). In the Catalan context it was critical to control SES, which includes parental education, occupation, foreign travel, and space and amenities available in the home, since Spanish identifiers are generally of lower SES (Miley, 2006), but 
higher in xenophobia (e.g., Erickson, 2011). SES was also relevant in terms of the historical context of the recent economic crisis, resulting in a sizable increase in social instability and unemployment in Catalonia at the time of this research (IDESCAT, 2014c) disproportionately affecting lower SES groups.

\section{Method}

\section{Participants}

High school students between 15 and 16 years old from 30 Catalan high schools (82 classrooms) participated in this study in spring 2014. Schools were selected in order to obtain a representative sample from all four Catalan provinces. Five were located within Barcelona's city limits, 8 in Greater Barcelona, and 17 elsewhere in Catalonia. They were diverse in size, overall socioeconomic status, and percentage of first- and second-generation immigrant students. Although 1709 students agreed to participate and filled out surveys, only those for whom all measures listed below were available, $n=1550$ ( $48.5 \%$ female) were included in the multilevel analyses. This included 382 participants $(24.6 \%)$ who were first- or secondgeneration immigrants (first-generation students were born in over 50 different countries). Of these, 106 (6.8\% of the total sample) were Muslim identifying, with 53\% born in Morocco, 9\% born in Pakistan, with 7\% each born elsewhere. The remaining Muslim-identifying immigrants, $31 \%$, were second-generation, with $24 \%$ of these having parents born in Morocco; other parents were born elsewhere. For native students, which included only four Muslims, religious background was not taken into account.

\section{Measures}

\section{Dependent variables}

National identity. Respondents indicated on 5-point scale (1 not at all to 5 very) to what extent they "felt or identified" as Catalan and as Spanish. We used two different measures of dual identification, based on approaches proposed in the ambivalent attitudes literature. ${ }^{3}$ First, 
borrowing from the Similarity Intensity Model (SIM) by Thompson and Zanna (1995), we calculated a dual identification score based on the following equation:

Dual Identification $(\mathrm{SIM})=\left(3^{*} \mathrm{C}-\mathrm{D}\right)$.

For our purposes, $\mathrm{C}$ is the weaker of the two identities, and $\mathrm{D}$ is the dominant identity of the two (either may be chosen if identities are equal). The highest scores are both high and of similar magnitude (e.g., $5=$ Catalan, $5=$ Spanish, 15 - $5=10$ ), the lowest scores (e.g., $5=$ Catalan, $1=$ Spanish or $1=$ Catalan, $5=$ Spanish, $3-5=-2$ ) are those that show conflicting magnitude regarding host national identification (Thompson \& Zanna, 1995; see also the "Study Overview" section of this paper). Since the lowest possible score is -2 , we added +2 to every score, thus changing the equation to Dual Identity $=2+(3 * \mathrm{C}-\mathrm{D})$. This was merely for convenience to ensure that lowest possible dual-identity endorsement is 0 given our 5-point measurement scales.

The second approach relied on the graduate threshold model (GTM) by Priester and Petty (1996), with dual identity calculated as:

$$
\text { Dual Identification }(\mathrm{GTM})=5 \mathrm{C} \cdot 5-\mathrm{D}^{1 / \mathrm{C}} \text {. }
$$

Referring to the examples above, the highest and lowest possible scores are 9.801 and 0 , respectively. $^{4}$

Xenophobia. A 7-item scale was created (Wilson-Daily et al., 2018), to assess xenophobic attitudes among adolescents (Cronbach's $\alpha=.83$ ). Participants were asked to imagine that a peer made a series of statements about "people who have arrived from other countries" and to rate the degree to which they agreed or disagreed with these statements $(1=$ strongly disagree to $5=$ strongly agree). Sample items included: "They take jobs away from people who were born here," "They are unfamiliar with the laws here and don't follow them," and "They help our economy grow" (reverse-coded). 


\section{Independent variables}

Immigrant background and immigrant categorization based on religion. Participants indicated whether their parents were born in Catalonia, elsewhere in Spain, or abroad. Those born abroad were prompted to specify their birthplace. Students were considered immigrants if both parents, or in cases of single parents, mother or father, were born abroad. Students with one native parent were considered natives (see Stanat \& Christensen, 2006). Muslim immigrants were those who self-identified as Muslim on close-ended multiple-choice item listing different religions. Non-Muslim immigrants were those who did not self-identify as Muslim on this same item.

By-practice and by-ascription views of Catalan identity. Students responded to seven items (1 strongly disagree to 5 strongly agree) on who they considered to be "Catalan". A principal component analysis with varimax rotation identified two distinct dimensions (see also Jones $\&$ Smith, 2001a, 2001b). The first we refer to as Catalan identity by practice on which 3 items were loaded: "The Catalans are people who live in Catalonia regardless of where they were born and whether or not they live here legally," "The Catalans are people who feel that they are from Catalonia," and "The Catalans are people who share the most common Catalan traditions and customs." The second dimension we call Catalan identity by ascription: "The Catalans are people that were born in Catalonia" and "Catalans are the people who live here legally." Two additional items related to Catalan language and multi-generational ancestry were eliminated due to cross-loadings. ${ }^{5}$

Age of arrival. Participants were asked how old they were when they arrived to Catalonia/Spain (if applicable). For our analyses, we created two categories: under 6 years and over 6 years spent in Catalonia (see Cummins, 1981; Rumbault, 2004). Natives and second-generation participants were assigned a 0 , and those who were not born in Catalonia or Spain and had arrived before the age of six were recoded as 1, and those after six as 2 . 
Spanish-language-origin connection. Students who indicated that they themselves, or at least one of their parents, were born in Spain, outside of Catalonia, $(n=413 ; 35.4 \%$ of natives) or in another Spanish-speaking country ( $n=176 ; 46.1 \%$ of immigrants) were dummy-coded into this category. This included students from Equatorial Guinea, for example, whose national language is Spanish.

Socio-economic status and gender. A standardized factor score was constructed based on highest parental educational attainment of either parent; frequency with which students had travelled abroad (if they had done so); whether participants had their own room, their own table for studying, and a computer and Internet access at home. In addition, the factor score included the highest occupational level of any parent, categorized according to the Spanish National Classification of Occupations or CNO-11 (INE, 2011). Participants also indicated their gender $(1=$ female, $0=$ male $)$.

\section{Data collection}

Students were surveyed in their classrooms by research team members as part of a larger study and assured that their answers would remain anonymous. All instruments were administered in Catalan. As with other international educational surveys (e.g., the Programme for International Student Assessment [PISA]), the questionnaires of students whose level of Catalan was deemed insufficient by their teachers, e.g., because they were recent arrivals to Catalonia, were not included (see Burns et al., 2011, p. 297).

\section{Data analysis}

Analyses were conducted in R using the lme4 package (Bates et al., 2016). A multilevel approach was used, which allowed us to handle the interdependence in our data as it occurred with students nested within classrooms, which themselves were nested within schools. Hence, we used a series of three-level models, in which we tested individual-level effects, classroomlevel effects, and cross-level interactions. School-level terms generally did not improve the 
models, and are therefore not reported. ${ }^{6}$ All continuous predictors were grand-mean centred. For each dependent variable, we tested four models: Model 1 included only main effects at the individual level (Level 1); Model 2 included both main effects and interaction effects at the individual level (Level 1); Model 3 added main effects at the classroom level (Level 2); and Model 4 finally included cross-level interaction terms. The four models were tested in sequence, and a model was selected when a subsequent model no longer improved model fit based on comparisons of -2 log likelihood, Akaike Information Criterion (AIC), and Schwartz's Bayesian Information Criterion (BIC).

\section{Results}

The central goal of our analyses was to first to examine predictors of Catalan and Spanish identification, as well as dual identification, i.e., joint identification with both. Table 1 revealed that Model 3 was the last to improve model fit for all pertinent dependent identification variables, with the likelihood ratio test showing significant model improvement compared to Model 2. Table 2 (columns 1-4) summarizes the model results.

\section{Catalan and Spanish identification}

A first inspection reveals that the intercept for Catalan identification is substantially higher than for Spanish identification, implying overall higher levels of Catalan national attachment. Next, the negative coefficient of Catalan identity on Spanish identity and Spanish identity on Catalan identity imply that, generally, students view these two identities as incompatible with one another. However, this appears to be contingent on immigration status: the significant interaction terms highlighted that, whereas for native-born students there is the abovementioned negative link from Spanish identification to Catalan identity, $b=-.23, p<.001$, this relationship is reversed for both Muslim immigrants, $b=.49, p<.001$, and non-Muslim immigrants, $b=.29, p<.001$. Likewise, significant interaction terms showed that among native-born students high levels of Catalan identification predicted lower levels of Spanish 
identification, $b=-.31, p<.001$. This relationship was again reversed among both Muslim immigrants, $b=.60, p<.001$ as well as non-Muslim immigrants, $b=.41, p<.001$. These findings imply that only native-born students perceived identification with Catalonia and Spain to be incompatible with each other, whereas immigrants were likely to identify with both at the same time. It is important to note that both groups of immigrants were significantly less likely to identify with Catalonia than their native-born peers, whereas there was no reliable difference between the two immigrant groups with regard to Spanish identification.

Still, among immigrants and non-immigrants alike, having been born in or having a parent from a Spanish-speaking country (i.e., Spain but not Catalonia, a Spanish-speaking Latin American country, etc.) was a positive predictor of Spanish identification and a negative predictor of Catalan identification.

When considering the by-practice (embracing traditions/personal feelings) versus byascription (birth/legality) dimensions of Catalan identity, respondents showed the conception of being Catalan as a matter of practice was positively related to high levels of Catalan identification among native-born students, $b=.11, p<.01$, as well as among Muslim immigrant students, $b=.28, p<.05$, with the relationship being significantly stronger among nonMuslim immigrant students than native students, $b=.32, p<.001$. These findings highlight that, especially for immigrants, identifying as Catalan is rooted in feeling Catalan and doing "Catalan things." However, the pattern varied for Catalan identity by ascription. Only native students identified more with Catalonia the more they felt that being Catalan implied being born in Catalonia and having a legal status there, $b=.18, p<.001$. However, as shown by the relevant interaction effects in the first column of Table 2, this relationship was held neither among Muslim nor among non-Muslim immigrant students, $b=-.12, p=.12$ and $b=-.04, p=$ .60 , respectively. In other words, immigrants seemed to base their sense of identification with Catalonia exclusively on Catalan practices and feeling Catalan, whereas for native-born 
students legality and birth in Catalonia were important. In fact, a comparison of coefficients implies that for native students their beliefs about identity-as-ascription was slightly more predictive of their level of identification than their beliefs about identity as practice $(b=.11$ vs. $b=.18)$.

Interestingly, conceptions of Catalan identity also related to Spanish identification. The more students viewed being Catalan to be a matter of practice, the less they identified with Spain, $b=-.28, p<.001$, again pointing to the sensed incompatibility between feeling Catalan and feeling Spanish. Yet, the more they viewed being Catalan as a matter of birth and legal status, the more they identified with Spain, $b=.14, p<.001$. The latter observation might be largely a reflection of the fact that, even when Catalonia is viewed as a separate nation, as of this writing, legally every Catalan citizen is also a Spanish citizen. That is, native students who view identity through an ascription (birth/legality) lens might be more likely to identify as both Catalan and Spanish. However, as indicated by significant interaction terms, both relationships were not reliable for non-Muslim immigrant students, $b=.02, p=.80$, and $b=-.07, p=.44$, respectively. Among Muslim immigrant students, nonsignificant interactions showed that relationships are not substantially different from those obtained for native students; yet, simple effects showed, as for non-Muslim immigrants, the respective relationships were not reliable, $b=-.09, p=.54$, and $b=.14, p=.26$.

A students' socioeconomic background had differential implications for identification with Catalonia and Spain. Whereas higher SES predicted greater Catalan identification, it also implied lower Spanish identification. Again, this pattern primarily manifested for native students, $b=.22, p<.001$ and $b=-.21, p<.001$. Whereas the individual-level relationships were consistent among both Muslim and non-Muslim immigrants, the link between SES and Spanish identification was non-significantly reversed among non-Muslim immigrant students, $b=.07, p=.41$. Notably, the lower the overall SES level of a student's class, the lower their 
identification with Spain (see Table 2). That is, a lower SES context seemed to relate to a weakened sense of Spanish identification.

\section{Dual identification}

Results for our two parallel measures of dual identification (SIM, GTM) converged (see Table 2, columns 3 and 4). Strikingly, both types of immigrant students scored substantially higher on dual identification compared to native-born students. This is consistent with the observation that, in contrast to native students, immigrant student responses revealed a positive correlation between Catalan and Spanish identification; i.e., immigrants tended to identify with both groups at the same time. However, this result must be viewed with caution. Whereas this finding indicates that immigrants were more likely to rate their identification with Catalonia and Spain equally, the absolute level of identification was substantially lower than among native students. For instance, a total of $27.4 \%$ of all native students rated being Catalan and Spanish as high or very high (a 4 or 5) on a 5-point scale. However, across immigrant groups, this higher dual identification was the case for only $3.5 \%$ of all the immigrant students. When examining, however, whether students exhibited at least a middling dualidentification ( 3 or higher on the 5-point scale), the proportion of native students increased to $41.4 \%$, and more drastically jumped to $32.7 \%$ among immigrants. ${ }^{7}$

Not surprisingly, Catalan and Spanish identification were related to the dual identification scores, simply because the latter included the former. Likewise, the interaction effects (Table 2, lower panel of column 3 and 4) must be interpreted as a consequence of the SIM and GTM formula assigned slightly more or less importance to Catalan versus Spanish identification in the computation of the dual identification score depending on which was more or less likely to become the $\mathrm{C}$ or $\mathrm{D}$ component (see above). However, the inclusion of both identification terms, and their interactions with immigration status ensures that the above group differences in dual identification (i.e., native vs. immigrant students) are not merely a reflec- 
tion of either Catalan or Spanish identification, but truly the result of joint identification with both groups.

Importantly, this analysis did not find any relationships between conceptions of Catalan identity (by-practice, by-ascription) and dual identification. In other words, how students think about what makes someone Catalan did not have any implications for whether they identified with both Catalonia and Spain simultaneously, even when conceptions of identity had implications for their identification with Catalonia or Spain by itself.

\section{Xenophobia}

Our final set of models addressed the implications of immigrant status, ethnic-national identifications and conceptions of Catalan identity for xenophobia. As shown in Table 1, the simplest model (including individual-level main effects only) was not improved by the addition of interaction effects or classroom level effects. Hence, we report findings from our Model 1 in the last column of Table 2.

First and not surprisingly, both Muslim and non-Muslim immigrant students held less xenophobic views than native students, reflecting that "newcomers" to a society held more favourable views concerning this very status as newcomers. Second, to the extent that students identified with Spain they were more likely to hold xenophobic views, consistent with previous work (e.g., Hjerm, 1998; Knudsen, 1997).

Catalan identification itself was unrelated to xenophobia. Yet, how students thought about being Catalan clearly did have implications for xenophobia. The more students believed that being Catalan was a matter of daily practice and subjective feeling, the less likely were they to hold xenophobic attitudes. However, the more they believed that there were clear and objective criteria, such as birth or legal status in Catalonia, the more they embraced xenophobic beliefs. Spanish identification, was linked to higher levels of xenophobia, even when students born, or with at least one parent born, in Spain (not Catalonia) or a Spanish-speaking 
country were less likely to hold such attitudes. This makes clear that subjective importance assigned to Spain, not merely one's birth place or parentage from Spain or Latin America, were predictive of xenophobia.

Lastly, dual identification was also negatively related to xenophobia. Especially in a model which controls for its constituent components (Catalan and Spanish identification) dual identification is a distinct predictor. ${ }^{8}$

\section{Discussion}

Catalonia is living a moment of national political turmoil, complicated by a recent six-fold increase in immigration. Much of the future of Catalonia and whether parts of its population will continue to seek the region's independence is related to national identification (Tormos et.al, 2015). In this regard, whether feeling Catalan and feeling Spanish are seen as compatible or incompatible with each other by future political participants is likely of central interest (Hierro \& Gallego, 2018; Hooghe \& Wilkenfeld, 2008).

Whereas national identification among native adults in Catalonia has received much larger-scale empirical attention, to our knowledge, our investigation is the first of its type to investigate national identification in adolescents - individuals who will soon reach maturity and are able to help shape Catalonia's future through voting and other forms of political participation. Likewise, our investigation is the first to include immigrant youth, a part of the population that embodies an important part of the dramatic social changes occurring in Catalonia.

Our multilevel investigation revealed that identity polarization in Catalonia, i.e., identifying either as Catalan or Spanish, is not confined to adult Catalan residents, but is also prevalent among the native adolescent population. In other words, although we employed measures of identity different from those commonly used in studies of adults in Catalonia (e.g., Hierro \& Gallego, 2018; Tormos et al., 2015), conceptually, our findings for native youth mirror their older counterparts in that being Catalan and being Spanish is viewed by 
many as incompatible, even when a substantial minority of dual-identifiers is present. Immigrants report overall lower levels of national identification, but do not seem to buy into incompatibility between feeling Catalan and feeling Spanish and are much more likely to dual-identify.

Over the long term this pattern may have some profoundly ironic consequences - and a long-term perspective is warranted because our focus was on adolescents, many of whom would turn into legal voting citizens in a few short years. On the one hand, we know that Catalan nationalists portray the Catalan identity as inherently inclusive (e.g., Conversi, 1990; Erickson, 2011; Woolard, 2016). The Catalan independence movement does reject identification with Spain, but displays openness to immigrants seemingly in hopes that nationalized immigrants might eventually support Catalan independence (Carlà, 2018). On the other hand, Spanish-identifying residents of Catalonia, and who are much less likely to support Catalan independence, are much more likely to oppose immigrants and immigration (see Wilson-Daily et al., 2018; cf. Wilson-Daily \& Kemmelmeier, 2019). Yet, it is precisely immigrant youth who find being both Catalan and Spanish compatible with each other, and who thus may not see a need for Catalan independence. Put differently, many of the native residents who strongly identify with Spain seem to oppose the influx of precisely the group that might be supportive of keeping Catalonia as part of Spain. Likewise, strong supporters of a Catalan national project might be precisely supportive of the group who, over the long term, might actually undermine their push for independence. Overall, our prediction is that as the growing immigrant population in Catalonia is nationalized or second generation immigrant youth come of voting age, chances of a successful referendum in favor of Catalan independence are likely to diminish.

Our data also provide important insight into youth conceptions of what determines national identity, which is only partially shared between native and immigrant youth. Outside 
of high Spanish identifiers, students seemed to embrace the current political discourse that the Catalan identity is permeable and open, accessible by sharing Catalan customs and feeling Catalan. Indeed, non-Muslim immigrant students, for example, seemed to subscribe to this idea even more than native students. Arguably, this reflects a success on the part of a Catalan movement that portrays itself as tolerant and cosmopolitan (e.g., Erickson, 2011; Woolard, 2016; but also Gibson et al., 2013). Yet, native students also felt that being Catalan was a matter of ascription, i.e., being born in Catalonia and having a legal status there, whereas immigrant students did not. This more objectivist Catalan identity entails the potential exclusion of newcomers to Catalonia, as reflected in our Catalan-by-ascription variable predicting higher levels of xenophobia. Overall, it is not surprising that for immigrant students whom they considered "Catalan" was not seen as a matter of ascription. Conceiving of being Catalan as a matter of practice, of feeling Catalan, and doing Catalan things is inherently more inviting to newcomers.

Surprisingly, we also found that different conceptions of Catalan identity predicted levels of Spanish identification. As briefly alluded to earlier, believing that being Catalan is a matter of practice was inversely related to identifying as Spanish. At the same time, the notion that Catalan was a matter of ascription was positively related to Spanish identification, similar to what was found for Catalan identification. We speculate that viewing Catalan as a matter of practice may reflect a generally more open-minded stance on matters of identity and the political status quo in Catalonia. From this perspective, viewing Catalan identity as in-practice and permeable may convey a rejection of Spain as the political unit of which Catalonia is a part.

In line with the literature (e.g., Erickson, 2011), Spanish identification was related to higher levels of xenophobia, but not Catalan identification. Muslim immigrants showed lower levels of xenophobia compared to non-Muslim immigrants, perhaps due to higher levels of discrimination toward Muslim immigrants in Catalonia even by other immigrant groups 
(Deusdad Ayala, 2009). Further speaking to the literature (e.g., Miley, 2006), lower SES negatively predicted Catalan identity (see also Wilson-Daily \& Kemmelmeier, 2019). And as hypothesized, among immigrants, later age of arrival and having been born or having at least one parent from Spain (but not Catalonia) or another Spanish-speaking country (cf. Petreñas et al., 2019) negatively predicted Catalan identification. Yet, contrary what was hypothesized, no great differences were observed between Muslim and non-Muslim immigrants regarding any of the host identification categories. The literature reveals that, in spite of Catalan insistence on inclusivity, immigrants do often face exclusion in Catalan secondary schools, institutional and otherwise (Deusdad-Ayala, 2009; Gibson et al., 2013; Petreñas et al., 2019). Nonetheless, our findings suggest that if indeed this type of exclusion does selectively target Muslim immigrants (Astor, 2016; Deusdad-Ayala, 2009), it does not affect their levels of Catalan, Spanish, or dual identification compared to non-Muslim immigrants.

As with all studies, our research is not without limitations. Our data, which were collected in 2014, offer a brief glimpse at the complex identity dynamics in Catalonia. It is unclear to what extent youth would have responded to the much more forceful 2017 attempt on the part of the Catalan independence movement to achieve its aim, the corresponding police brutality, the subsequent jailing and criminal conviction of Catalan leaders, and the Spanish government`s imposed direct rule of Catalonia (Barceló, 2018; Garrido-Muñoz, 2018; "Violent clashes," 2019). In particular, it remains an open question whose identifications were potentially affected by these events.

Arguably, an omission in the present research was that we focused exclusively on conceptions of Catalan national identity, but not conceptions of Spanish identity. It would have been interesting to observe whether conceptions of Catalan identity as either ascriptionbased or based on personal practice match the conceptions of Spanish identity. Though we speculate that Spanish identity is seen as much more ascription-based, we must be open to the 
possibility that adolescents residing in Catalonia vary to the extent that they entertain much more practice-based notions of national identity, regardless of what they think about Catalonia or Spain. Conversely, providing concrete evidence that practice-based conception of Spanish is rejected in favour of a more ascription-based Spanish would offer a stronger argument that the comparative accessibility of the Catalan identity is indeed what attracts and persuades immigrants to identify as Catalan.

The observation that the classroom-level variables were not related to our identity variables (with the exception of low-classroom-SES predicting Spanish identity) is surprising and diverges from the results of earlier studies (see Hierro, 2015, Pagès \& González Monfort, 2010). Overall, little variability was observed among classrooms or schools, implying that our participants' identification is largely related to individual-level, and not school factors (but see Endnote 6). Studies drawing from the same data set did show that the school context is influential in Catalonia regarding attitudes toward political engagement (Wilson-Daily \& Kemmelmeier, 2019) and classroom make-up in attitudes toward different conceptions of diversity (Wilson-Daily et al., 2018). We cannot provide a cogent explanation for this apparent discrepancy. We speculate that, especially for immigrant youth, parental attitudes and students' own personal experiences (negative and positive) with members identifying with different national groups are of particular relevance. Schools represent a central life context for adolescents, and it is thus possible that identity-defining personal experiences might occur within the context of personal relationships with classmates (e.g., friendships). With students having both positive and negative experience with classmates, our current approach might have been too coarse by averaging across the mix of these experiences. That is, our approach could have resulted in the illusion that classrooms do not matter, when indeed are central for critical relationships. This is an area worthy of future study. 


\section{Endnotes:}

1. Centre d'Estudis d'Opinió (CEO), available at http://ceo.gencat.cat/ accessed 05 September 2019.

2. Note that this method does not inherently assume that one of the identities is positive and the other negative; rather, the focus is merely on whether the actual patterns of identification with the two identities reflect whether these identities are compatible or incompatible with each other.

3. To operationalize dual identification, previous research (including our own: Wilson-Daily, 2018) has often used the multiplicative interaction term made up of two separate identification variables when dual identification served as a predictor variable. We employed dual identification as a predictor only in our analysis of xenophobia (Table 1, bottom panel; Table 2, column 5). When repeating these analyses with a multiplicative interaction, results led to the same conclusions as those reported here. In other analyses, we treat dual identification as dependent variable (Table 1, middle panels; Table 2, columns 3 and 4).

4. Uz et al. (2009) and Uz and Kemmelmeier (2014) employed the same two models (SIM, GTM) to calculate a score reflecting what the authors termed "ambivalent identification." However, scores were based on respondents' stated response to be close to (approach) or to be distant from (avoid) a particular identity. Here, SIM and GTM are being used to assess identification with two competing, if not for many respondents in compatible group memberships.

5. Whereas as speaking the national language is sometimes treated as evidence of an ascribed ethnic identity, recall that in Catalonia speaking Catalan is a critical aspect of public life. Hence, it is not surprising that this item loaded on both dimensions.

6. The only exception was school location. Students in the schools located within Barcelona's city limits were less xenophobic than students in schools in Greater Barcelona or elsewhere in Catalonia. In turn, compared to elsewhere in Catalonia, dual identification was higher in Barcelona and Greater Barcelona. These patterns are consistent with previous research (Astor, 2016; Rodon \& Guinjoan, 2018). However, because location did not qualify any of our present findings, it is not included here.

7. As apparent from Table 2, native students scored on average higher in terms of the Catalan identification than their Spanish identification ( $M=3.95$ vs. 3.23). Among Muslim immigrant students ( $M=3.08$ vs. 3.42$)$ and non-Muslim immigrant students $(M=3.08$ vs. 3.38), differences in average levels of identification were reversed and smaller in size.

8. The reported analyses rely on the GTM score for dual identification. Because analyses relying on the SIM score produced virtually identical results, they are not reported here (see Table 2). 


\section{References}

Adams, M. (2007). Unlikely Utopia: The surprising triumph of Canadian pluralism. Viking.

Astor, A. (2016). Social position and place-protective action in a new immigration context: Understanding anti-mosque campaigns in Catalonia. International Migration Review, 50(1), 95-132.

Barceló, J. (2018). Batons and ballots: The effectiveness of state violence in fighting against Catalan separatism. Research \& Politics, 5(2), 1-9.

Bates, D. M., Maechler, M., Bolker, B., \& Walker, S. (2016). lme4: Mixed-effects modeling with R. http://lme4.r-forge.r-project.org/book

Billig, M. (1995). Banal nationalism. Sage.

Blad, C., \& Couton, P. (2009). The rise of an intercultural nation: Immigration, diversity and nationhood in Quebec. Journal of Ethnic and Migration Studies, 35(4), 645-667.

Burns, S., Wang, X., \& Henning, A. (Eds.). (2011). NCES handbook of survey methods, NCES 2011-609. National Center for Education Statistics.

Carlà, A. (2018). Land of welcome, land of fear: Explaining approaches to 'new' diversity in Catalonia and South Tyrol. Journal of Ethnic and Migration Studies, 44(7), 1098-1116.

Conversi, D. (1990). Language or race? The choice of core values in the development of Catalan and Basque nationalisms. Ethnic and Racial Studies, 13(1), 50-70.

Conversi, D., \& Jeram, S. (2017). Despite the crisis: The resilience of intercultural nationalism in Catalonia. International Migration, 55(2), 53-67.

Cummins, J. (1981). Age on arrival and immigrant second language learning in Canada: A reassessment. Applied Linguistics, 2, 132-149.

Deusdad Ayala, B. (2009). Immigrants a les escoles [Immigrants in schools]. Pagès Editors.

Ellemers, N. (1993). The influence of socio-structural variables on identity management strategies. European Review of Social Psychology, 4(1), 27-57.

Erickson, B. (2011). Utopian virtues: Muslim neighbors, ritual sociality, and the politics of convivència. American Ethnologist, 38(1), 114-131.

Fernández-i-Marín, X., Rodon, T., \& Serrano, I. (2013, September). Decided or undecided: An investigation of individual's (in)decision to Catalan independence. Paper presented at the XI Congreso de la Asociación Española de Ciencia Política, Sevilla, Spain. http://www.aecpa.es/uploads/files/modules/congress/11/papers/823.pdf

Franco-Guillén, N. (2015). Quin poble? Immigració i procés sobiranista a Catalunya. Eines per a l'Esquerra Nacional, (22), 80-89.

García, C. (2013). Strategic communication applied to nation building in Spain: the experience of the Catalan region. Public Relations Review, 39(5), 558-562. 
Garrido-Muñoz, A. (2018). Prime Minister v. Parliament of Catalonia. American Journal of International Law, 112(1), 80-88.

Gibler, D. M., Hutchison, M. L., \& Miller, S. V. (2012). Individual identity attachments and international conflict: The importance of territorial threat. Comparative Political Studies, 45(12), 1655-1683.

Gibson, M., Carrasco, S., Pàmies, J., Ponferrada, M., \& Río-Rojas, A. (2013). Different systems, similar results: Youth of Immigrant origin at school in California and Catalonia. In Alba, R., \& Holdaway, J. (Eds.), The children of immigrants at school: A comparative look at integration in the United States and Western Europe (pp. 84-119). New York University Press.

Gilroy, P. (2002). There ain't no black in the Union Jack: The cultural politics of race and nation. Routledge Classics.

Guibernau, M. (2013). Secessionism in Catalonia: After democracy. Ethnopolitics, 12, 368393.

Hayes, B. C., \& McAllister, I. (2009). Religion, identity and community relations among adults and young adults in Northern Ireland. Journal of Youth Studies, 12(4), 385-403.

Hierro, M. J. (2015). Crafting identities in a multinational context: Evidence from Catalonia. Nations and Nationalism, 21(3), 461-482.

Hierro, M. J., \& Gallego, A. (2018). Identities in between: Political conflict and ethnonational identities in multicultural states. Journal of Conflict Resolution, 62(6), 1314-1339.

Hjerm, M. (2001). Education, xenophobia and nationalism: A comparative analysis. Journal of Ethnic and Migration Studies, 27(1), 37-60.

Hooghe, M., \& Wilkenfeld, B. (2008). The stability of political attitudes and behaviors across adolescence and early adulthood: A comparison of survey data on adolescents and young adults in eight countries. Journal of Youth and Adolescence, 37(2), 155-167.

Houston, J. E., Crozier, W. R., \& Walker, P. (1990). The assessment of ethnic sensitivity among Northern Ireland schoolchildren. British Journal of Developmental Psychology, $8(4), 419-422$.

Huguet, À., \& Janés, J. (2008). Mother tongue as a determining variable in language attitudes. The case of immigrant Latin American students in Spain. International Journal of Bilingual Education and Bilingualism 8(4), 247-60.

IDESCAT (2014a). Evolució de la població total i estrangera. 2000-2018 Catalunya. Institut d'Estadística de Catalunya, Generalitat de Catalunya. https://www.idescat.cat/poblacioestrangera/?b=0

IDESCAT (2014b). Població estrangera per països. 2018 Catalunya. Institut d'Estadística de Catalunya, Generalitat de Catalunya. https://www.idescat.cat/poblacioestrangera/?b=12

IDESCAT (2014c). Taxes d'activitat, ocupació i atur. Per sexe i grups d'edat. Catalunya. I trimestre. Institut d'Estadística de Catalunya, Generalitat de Catalunya. 
http://www.idescat.cat/economia/inec?tc $=3 \& \mathrm{id}=0608 \& \mathrm{dt}=201401 \& \mathrm{x}=10 \& \mathrm{y}=7$

INE (2011). National classification of occupations (CNO-11). Instituto Nacional de Estadística.

http://www.ine.es/jaxi/menu.do;jsessionid=E450B79A3E7D959B08329DCB633D0A09.ja xi01?type $=$ pcaxis $\&$ path $=/ \mathrm{t} 40 /$ cno $11 \&$ file $=$ inebase $\& \mathrm{~L}=1$

Janmaat, J. G. (2006). Popular conceptions of nationhood in old and new European member states: Partial support for the ethnic-civic framework. Ethnic and Racial Studies, 29(1), 5078.

Jeram, S. (2013). Immigrants and the Basque nation: Diversity as a new marker of identity. Ethnic and Racial Studies, 36(11),1770-1788.

Jones, F. L., \& Smith, P. (2001a). Diversity and commonality in national identities: An exploratory analysis of cross-national patterns. Journal of Sociology, 37(1), 45-63.

Jones, F. L., \& Smith, P. (2001b). Individual and societal bases of national identity. A comparative multi-level analysis. European Sociological Review, 17(2), 103-118.

Klandermans, P. G. (2014). Identity politics and politicized identities: Identity processes and the dynamics of protest. Political Psychology, 35(1), 1-22.

Knudsen, K. (1997). Scandinavian neighbours with different character? Attitudes toward immigrants and national identity in Norway and Sweden. Acta Sociologica, 40(3), 223243.

Kohn, H. (1944). The Idea of Nationalism: A Study in Its Origins and Background. Macmillan.

Kunovich, R. M. (2009). The sources and consequences of national identification. American Sociological Review, 74(4), 573-593.

Kymlicka, W. (2001). Politics in the vernacular: Nationalism, multiculturalism, and citizenship. Oxford University Press.

Larsen, C. A. (2017). Revitalizing the 'civic' and 'ethnic' distinction. Perceptions of nationhood across two dimensions, 44 countries and two decades. Nations and Nationalism, 23(4), 970-993.

Martí, D., \& Cetrà, D. (2016). The 2015 Catalan election: a de facto referendum on independence? Regional \& Federal Studies, 26(1), 107-119.

Martínez-Herrera, E. (2002). From nation-building to building identification with political communities: consequences of political decentralisation in Spain, the Basque Country, Catalonia and Galicia, 1978-2001. European Journal of Political Research, 41(4), 421453.

Meece, J. L., \& Eccles, J. S. (Eds.). (2010). Handbook of research on schools, schooling, and human development. Routledge.

Miley, T. J. (2006). Nacionalismo y Política Lingüística: El Caso de Cataluña. Centro de 
Estudios Políticos y Constitucionales.

Orriols, L., \& Rodon, T. (2016). The 2015 Catalan election: The independence bid at the polls. South European Society and Politics, 21(3), 359-381.

Pagès, J., \& González Monfort, N. (2010). La construcció de les identitats i l'ensenyament de les ciències socials, de la geografia i de la història. Universitat Autònoma de Barcelona.

Petreñas, C., Ianos, A., Lapresta, C., \& Sansó, C. (2019). Acculturation strategies and attitudes and their relationship with the identification of descendants of migrants in the Catalan school context. Journal of Youth Studies, DOI: 10.1080/13676261.2019.1682532

Priester, J. R., \& Petty, R. E. (1996). The gradual threshold model of ambivalence: relating the positive and negative bases of attitudes to subjective ambivalence. Journal of Personality and Social Psychology, 71(3), 431.

Reitz, J. G., Simon, P., \& Laxer, E. (2017). Muslims' social inclusion and exclusion in France, Québec, and Canada: Does national context matter? Journal of Ethnic and Migration Studies, 43(15), 2473-2498.

Repke, L., \& Benet-Martínez, V. (2018). The (diverse) company you keep: Content and structure of immigrants' social networks as a window into intercultural relations in Catalonia. Journal of Cross-Cultural Psychology, 49(6), 924-944.

Rico, G., \& Jennings, M. K. (2012). The intergenerational transmission of contending place identities. Political Psychology, 33(5), 723-742.

Rodon, T., \& Guinjoan, M. (2018). When the context matters: Identity, secession and the spatial dimension in Catalonia. Political Geography, 63, 75-87.

Rumbault, R. G. (2004). Ages, life stages, and generational cohorts: Decomposing the immigrant first and second generations in the United States. International Migration Review, 38(3), 1160-1205.

Scheve, K. F., \& Slaughter, M. J. (2001). Labor market competition and individual preferences over immigration policy. Review of Economics and Statistics, 83(1), 133-145.

Schwartz, S. J., Côté, J. E., \& Arnett, J. J. (2005). Identity and agency in emerging adulthood: Two developmental routes in the individualization process. Youth \& Society, 37(2), 201229.

Serrano, I. (2013). Just a matter of identity? Support for independence in Catalonia. Regional \& Federal Studies, 23(5), 523-545.

Shulman, S. (2002). Challenging the civic/ethnic and West/East dichotomies in the study of nationalism. Comparative Political Studies 35(5), 554-85.

Stanat, P., \& Christensen, G. (2006). Where immigrant students succeed: A comparative review of performance and engagement in PISA 2003. OECD Publications. 
Thompson, M. M., \& Zanna, M. P. (1995). The conflicted individual: Personality-based and domain-specific antecedents of ambivalent social attitudes. Journal of Personality, 63, 259-288.

Tormos, R., Muñoz, J., \& Hierro, M. J. (2015). Identificació nacional: Causa o conseqüiència? Els efectes del debat sobre la independència en la identitat dels catalans. Generalitat de Catalunya, CEO.

http://ceo.gencat.cat/web/.content/30_estudis/03_publicacions/Papers_treball/ 2015_05_05_papers_treball_idnacweb.pdf

Tsang, A. K. T., Irving, H., Alaggia, R., Chau, S. B., \& Benjamin, M. (2003). Negotiating ethnic identity in Canada: The case of the "satellite children". Youth \& Society, 34(3), 359384.

Uz, I., \& Kemmelmeier, M. (2014). Islamist terrorism as identity threat: the case of ambivalent identification and self - stereotyping among Turkish Muslims. Journal of Applied Social Psychology, 44(10), 660-671.

Uz, I., Kemmelmeier, M., \& Yetkin, E. (2009). Effects of Islamist terror in Muslim students: evidence from Turkey in the wake of the November 2003 attacks. Behavioral Sciences of Terrorism and Political Aggression, 1(2), 111-126.

Verkuyten, M., \& Reijerse, A. (2008). Intergroup structure and identity management among ethnic minority and majority groups: The interactive effects of perceived stability, legitimacy, and permeability. European Journal of Social Psychology, 38(1), 106-127.

Violent clashes over Catalan separatist leaders' prison terms. (2019, October 14). The Guardian. https://www.theguardian.com/world/2019/oct/14/catalan-separatist-leadersgiven-lengthy-prison-sentences

Wainryb, C., \& Recchia, H. (2015). Youths' constructions of meanings about experiences with political conflict: Implications for processes of identity development. In K. McLean \& M. Syed (Eds.), The Oxford Handbook of Identity Development (pp. 369-388). Oxford University Press.

Wilson-Daily, A. E., \& Kemmelmeier, M. (2019). Youth Perceptions of Voting Participation in the Midst of Catalonia's Active Struggle for Independence. Youth \& Society. https://doi.org/10.1177/0044118X19840965

Wilson-Daily, A. E., Kemmelmeier, M., \& Prats, J. (2018). Intergroup contact versus conflict in Catalan high schools: A multilevel analysis of adolescent attitudes toward immigration and diversity. International Journal of Intercultural Relations, 64, 12-28.

Woolard, K. A. (2016). Singular and plural: Ideologies of linguistic authority in 21st century Catalonia. Oxford University Press. 
Table 1. Data for determining optimal model fit for the 5 dependent variables.

\begin{tabular}{llllll}
\hline \multicolumn{1}{c}{ DV } & Model & Df & $\begin{array}{c}\text { Log } \\
\text { Likelihood }\end{array}$ & BIC & AIC \\
\hline Catalan identification & 1 & 14 & -2362.9 & 4828.6 & 4753.8 \\
& 2 & 18 & $-2357.0^{*}$ & 4846.2 & 4750.0 \\
& 3 & 26 & $\mathbf{- 2 2 8 3 . 1}^{* * * *}$ & $\mathbf{4 7 5 7 . 3}$ & $\mathbf{4 6 1 8 . 3}$ \\
& 4 & 37 & $-2270.2^{* *}$ & 4812.2 & 4614.4 \\
\hline Spanish identification & 1 & 14 & -2596.6 & 5296.1 & 5221.2 \\
& 2 & 18 & $-2590.7^{*}$ & 5313.6 & 5217.4 \\
& 3 & 26 & $\mathbf{- 2 4 7 5 . 7 ^ { * * * }}$ & $\mathbf{5 1 4 2 . 4}$ & $\mathbf{5 0 0 3 . 4}$ \\
& 4 & 37 & -2470.1 & 5212.0 & 5014.2 \\
\hline Dual identification & 1 & 15 & -3724.8 & 7559.9 & 7479.7 \\
(SIM) & 2 & 19 & $-3720.6^{+}$ & 7580.7 & 7479.2 \\
& 3 & 29 & $\mathbf{- 3 5 6 2 . 9}$ & $\mathbf{7 3 3 8 *}$ & $\mathbf{7 1 8 3 . 8}$ \\
& 4 & 40 & -3560.1 & 7414.1 & 7200.3 \\
\hline Dual identification & 1 & 15 & -3462.6 & 7035.3 & 6955.1 \\
(GTM) & 2 & 19 & -3459.1 & 7057.7 & 6956.2 \\
& 3 & 29 & $\mathbf{- 3 3 0 6 . 2 ^ { * * * * }}$ & $\mathbf{6 8 2 5 . 5}$ & $\mathbf{6 6 7 0 . 5}$ \\
& 4 & 40 & -3302.6 & 6899.1 & 6685.3 \\
\hline Xenophobia & 1 & 16 & $\mathbf{- 1 4 8 5 . 8}$ & $\mathbf{3 0 8 8 . 8}$ & $\mathbf{3 0 0 3 . 5}$ \\
& 2 & 20 & -1483.6 & 3113.8 & 3007.2 \\
& 3 & 32 & -1475.8 & 3186.2 & 3015.7 \\
& 4 & 43 & -1469.4 & 3254.1 & 3024.8 \\
\hline
\end{tabular}

$* p<.05 ; * * p<.01 ; * * * p<.001$.

Note. 1 = Level 1 model; $2=$ Level-1 and Level- 2 model; $3=$ Level- 1 and -2 model only, within Level-1 interactions; 4 = Level-1 and -2 model only, with within Level-1 interactions and cross-level interactions. Asterisks levels refer to model fit comparisons between a model and preceding, less complex alternative model. Selected models are bolded (superior compare to previous model with regard to log likelihood, BIC and AIC).

$\mathrm{Df}=$ degrees of freedom.

LogLik = Likelihood ratio.

$\mathrm{BIC}=$ Bayesian information criterion.

$\mathrm{AIC}=$ Akaike information criterion. 
Table 2. Final models of multilevel analysis for Catalan Identity, Spanish Identity, Dual Identity (SIM and GTM), and Xenophobia

\section{Intercept}

Level 1(Individual)

Female $(0=$ male $)$

Age of arrival $(0-6$ years $)$

Age of arrival (7+ years)

Socioeconomic status (SES)

Non-Muslim immigrant

Muslim immigrant

Spanish-lang. origin connection

Cat. ID by practice

Cat. ID by ascription

Catalan identification

Spanish identification

Dual identification (GTM)

Level 1 Interactions

Non-Muslim Immi. X Cat. ID by practice

Muslim Immi. X Cat. ID by practice

Non-Muslim Cat X ID by ascription

Muslim Cat. ID X ascription

Non-Muslim Immi. X Catalan ident.

Muslim Immi. X Catalan ident.

Non-Muslim Immi. X Span. ident.

Muslim Immi. * Span. ident.

Non-Muslim Immi X SES

Muslim Immi X SES

Level 2 (Classroom)

Socioeconomic status (class \%)

Non-Muslim immigrants (class \%)

Muslim immigrants (class \%)

Spanish-lang. origin conn. (class \%)

Random components

Level 1 (individual)

Level 2 (classroom)

Level 3 (school)

\begin{tabular}{lcl}
\multicolumn{3}{c}{ Catalan identity } \\
\hline \multicolumn{1}{c}{$b$} & \multicolumn{1}{c}{$s e$} & \multicolumn{1}{c}{$t$} \\
\hline 3.948 & $(.059)$ \\
& & \\
.129 & $(.054)$ & $2.37^{*}$ \\
-.259 & $(.171)$ & -1.52 \\
-.472 & $(.171)$ & $-2.76^{* *}$ \\
.222 & $(.040)$ & $5.50^{* * *}$ \\
-.959 & $(.160)$ & $-5.99^{* * *}$ \\
-.868 & $(.228)$ & $-3.80^{* * *}$ \\
-.303 & $(.063)$ & $-4.82^{* * *}$ \\
.114 & $(.037)$ & $3.06^{* *}$ \\
.176 & $(.034)$ & $5.15^{* * *}$ \\
& - & \\
-.225 & $(.024)$ & $-9.28^{* * *}$
\end{tabular}

\begin{tabular}{cc}
\multicolumn{3}{c}{ Spanish identity } \\
\hline$b$ & se
\end{tabular}

\begin{tabular}{ccc}
\multicolumn{3}{c}{ Dual identity (SIM) } \\
\hline$b$ & $s e$ & $t$ \\
2.329 & $(.119)$
\end{tabular}

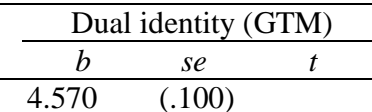

$\begin{array}{lll}.167 & (.061) & 2.73^{* *} \\ -.526 & (.193) & -2.72^{* *} \\ -.794 & (.192) & -4.14^{* * *} \\ -.206 & (.046) & -4.47^{* * *} \\ .150 & (.186) & .81 \\ .190 & (.268) & .71 \\ .422 & (.071) & 5.93^{* * *} \\ -.280 & (.041) & -6.78^{* * *} \\ .139 & (.039) & 3.57^{* * *} \\ -.306 & (.031) & -9.74^{* * *}\end{array}$

$\begin{array}{lll}.031 \quad(.124) & .25\end{array}$

$\begin{array}{lll}-.243 & (.395) & -.62\end{array}$

$\begin{array}{lll}.091 \quad(.398) & .23\end{array}$

$\begin{array}{lll}053 & (.094) & .57\end{array}$

$2.158 \quad(.382) \quad 5.65^{* * *}$

2.666 (.545) $4.89^{* * *}$

$\begin{array}{lll}.227 & (.145) & 1.56\end{array}$

$\begin{array}{lll}054 & (.085) & .63\end{array}$

$\begin{array}{lll}.031 \quad(.079) & .39 \\ 1.579 & (.066) & 23.85 \%\end{array}$

$1.579 \quad(.066) \quad 23.85^{* * *}$

$2.240 \quad(.058) \quad 38.84^{* * *}$

$\begin{array}{lll}.010 & (.105) & .09\end{array}$

$\begin{array}{lll}.0173 & (.335) & -.52\end{array}$

$\begin{array}{lll}.078 \quad(.337) & .23\end{array}$

$\begin{array}{lll}.025 & (.079) & .31\end{array}$

$1.767 \quad(.324) 5.46^{* * *}$

$1.939 \quad(.462) 4.20^{* * *}$

$\begin{array}{lll}109 & (.123) & .89\end{array}$

$\begin{array}{lll}.069 & (.072) \quad .96\end{array}$

$\begin{array}{lll}.061 \quad(.067) & .91 \\ 1.203 & (.056) & 21.44\end{array}$

$1.203 \quad(.056) 21.44^{* * *}$

$1.908 \quad(.049) 39.03^{* * * *}$

\begin{tabular}{ccc}
\multicolumn{3}{c}{ Xenophobia } \\
\cline { 2 - 3 } se & $t$ \\
\hline 3.070 & $(.053)$ &
\end{tabular}

$\begin{array}{lll}-.070 & (.033) & -2.12^{*} \\ .076 & (.102) & .75 \\ .151 & (.101) & 1.50 \\ -.070 & (.021) & -3.41^{* * *} \\ -.616 & (.095) & -6.52^{* * *} \\ -.704 & (.099) & -7.14^{* * *} \\ -.077 & (.038) & -2.04^{*} \\ -.138 & (.019) & -7.13^{* * *} \\ .066 & (.018) & 3.61^{* * *} \\ .000 & (.016) & .00 \\ .059 & (.016) & 3.58^{* * *} \\ -.029 & (.007) & -4.05^{* * *}\end{array}$

$\begin{array}{lll}.209 & (.080) & 2.62^{* *} \\ .162 & (.129) & 1.26 \\ -.215 & (.084) & -2.58^{* *} \\ -.294 & (.114) & -2.60^{* *}\end{array}$

$\begin{array}{lll}.301 & (.093) & 3.24^{* *} \\ .191 & (.151) & 1.27 \\ -.205 & (.094) & -2.17^{*} \\ -.002 & (.127) & -.02 \\ .719 & (.066) & 10.91^{* * *} \\ .910 & (.110) & 8.30^{* * *}\end{array}$

$-.130$

(.189) $\quad-.69$

$\begin{array}{lll}-.127 & (.307) & -.41\end{array}$

$\begin{array}{lll}-.102 & (.192) & -.53\end{array}$

$\begin{array}{lll}-.154 & (.261) & -.59\end{array}$

$\begin{array}{lll}-.169 & (.141) & -1.20\end{array}$

$\begin{array}{lll}-.800 & (.275) & -2.91^{* *}\end{array}$

$-2.178 \quad(.129)-16.86^{* * *}$

$-1.549 \quad(.237)-6.53^{* * *}$

$.276 \quad(.092) \quad 3.00^{* *}$

$\begin{array}{lll}-.421 & (.186) & -2.27^{*}\end{array}$

$\begin{array}{lll}-.057 & (.315) & -.18\end{array}$

$-.235$

$$
\text { - }
$$

(.007) $-4.05^{\text {*** }}$

$\begin{array}{ll}(.315) & -.18 \\ & \end{array}$

$\begin{array}{lll}-.004 & (.001) & -2.70 \\ -.006 & (.004) & -1.45\end{array}$

$\begin{array}{lll}-.004 & (.006) & -.75\end{array}$

$\begin{array}{lll}.001 \quad(.003) \quad .44 & 004\end{array}$

$\begin{array}{lll}.002 & (.002) & .84 \\ .008 & (.007) & 1.08 \\ -.005 & (.011) & -.50 \\ .008 & (.005) & 1.53\end{array}$

$-.235$

(.160) -1.47

(.260).- .79

(.162).- .56

(.221).- .55

(.119) $\quad .55$

(.233) $-2.57^{*}$

$\begin{array}{lll}.598 & (.233) & -2.57 \\ -1.869 & (.110) & -17.07^{* * *} \\ -1.219 & (.201) & -6.06\end{array}$

$-1.219 \quad(.201)-6.06^{* * *}$

$-.354 \quad(.157)-2.25$

$\begin{array}{lll}-.083 \quad(.267) & -.31\end{array}$

$003 \quad(.002) 1.29$

$\begin{array}{lll}.001 \quad(.006) & .21\end{array}$

$\begin{array}{lll}000 \quad(.009) \quad .04 & 000\end{array}$

$007 \quad(.004) 1.69$

$\begin{array}{llll}1.3947 & 5.6840 & 4.0917 & .3972 \\ .0000 & .1547 & .0962 & .0138 \\ .0695 & .0000 & .0000 & .0187\end{array}$

${ }^{*} p<.05 ; * * p<.01 ; * * * p<.001$. Note. $\mathbf{X}$ Denotes interaction; ${ }^{\text {a }}$ Coded $0=$ native, $1=$ immigrant. 